SF 453

.G5

Copy 1

\title{
The New Zealand Red Rabbit
}

\section{and Rabbit Culture}

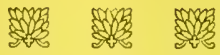 \\ C. P. GILMORE
}

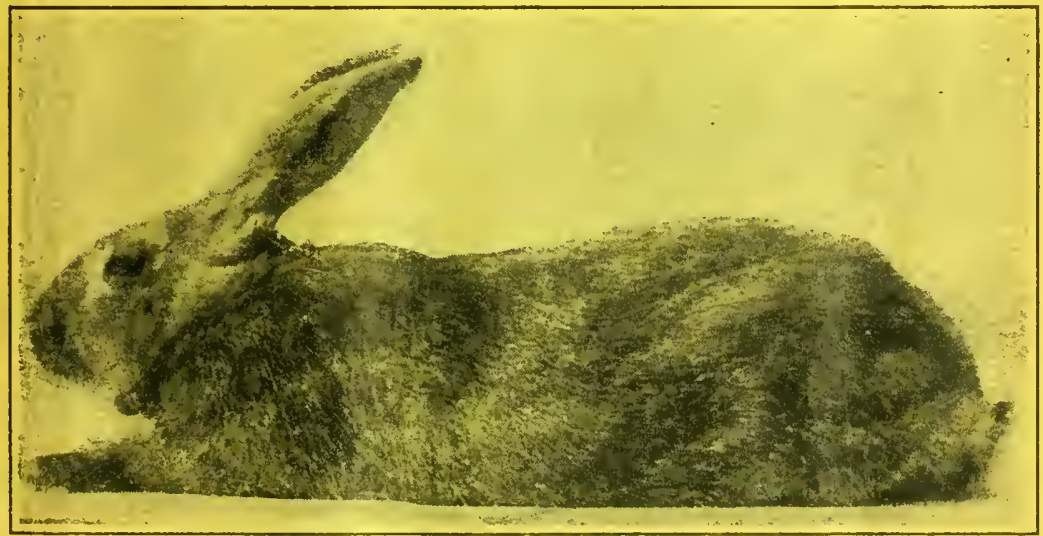

"RANGITERIA"

(Meaning "Gentleman" in the language of the New Zealander). A Gilmore Farm Registered New Zealand Stud Buck. Note the splendid, medium long body and the long, well shaped ears. First prize Sr. Buck, Los Angeles, California, January, 1917. 


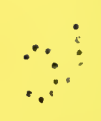




\section{The New Zealand Red Rabbit}

\section{and Rabbit Culture}

DEVOTED TO THE CARE AND BREEDING OF THE

POPULAR NEW ZEALAND RED RABBIT

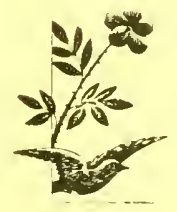

FIRST EDITION

Published by

Pacific Coast Publishing Company

Santa Barbara, California 


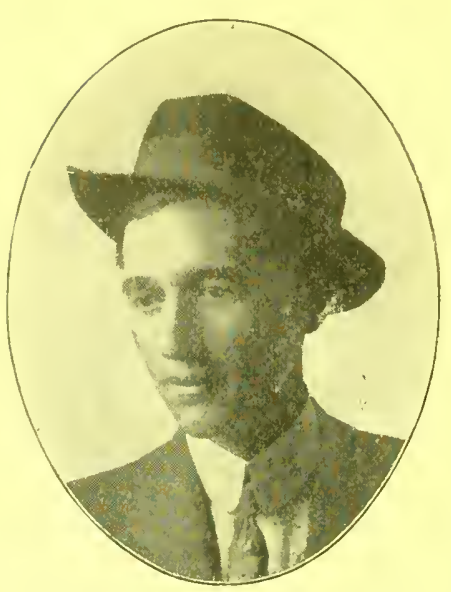

. 95

The aim of this little book is to enlighten all those interested in the New Zealand Red Rabbit and to help them to attain a degree of success that without its aid would require a much longer period of time and probably a much larger expenditure of capital.

It is to familiarize breeders with the correctness of type and culor markings of this splendid rabbit so as to enable them to direct with intelligence their efforts to secure better quality in their breeding stock.

While the book is devoted principally to the New Zealand Red, I have tried to give enough general rabbit information to make the book well worth the price to anyone interested in rabbits; few breeders are more successful than I, and what I have written is hased upon my successful methods.

Yours very truly,

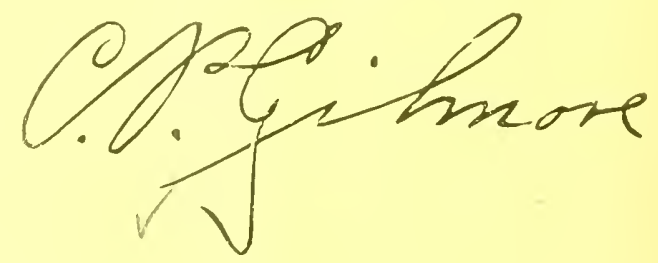

(C) $(11.415 \div 1155$

MAR -6 1917 
HOUSING, BREEDING, FEEDING AND GENERAL CARE OF NEW

\section{ZEALAND REDS}

(The following applies to practically all breeds of rabbits.)

In housing rabbits there are three essentials to keep in mind, no matter what kind of climate or what part of the world, you live in. They are: Plenty of sunlight, pure fresh air and dry clean floors. If you give these to your rabbits your troubles in this be built on the order of the eastern poultry houses, built as a shed, leaving one side open and using a burlap curtain during cold nights and storms, or better still have a shed with large doors or windows on all sides that can be opened through the day and closed at night-leaving one side open with the burlap curtain at all times.

Seli-cleaning hutches could be used in these sherls, thereby eliminating much of the work and making a sanitary rabbitry. We have discovered

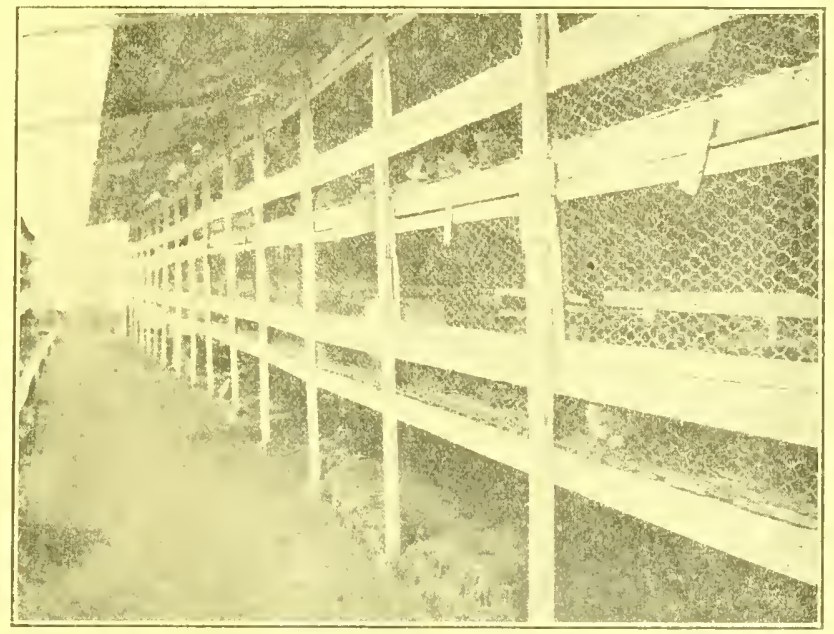

A ROW OF GHLMORE'S SELF-CLEANING HUTCHES

This picture was taken over a year ago, since then we have remodeled the entire rabbitry; the appearance of the hutches, however, is very much the same

line are over. By sunlight I do not mean direct sunshine, but the air that the sun shines on must be allowed to reach the rabbits. A great number, in fact most beginners, make the mistake of placing their rabbits off in the corner of a dark barn, in a dark cellar, or in some other place that has practically no ventilation. This is especially so in the cold states. Now a rabbit can stand a great deal of cold if the direct wind is not allowed to blow on it. In California hutches can be built in the open, having curtains for protection during the winter; in other states an ideal rabbitry should a method which enables one to bed rabbits in our self-cleaning hutches and they still maintain their selfcleaning efficiency. The real merit of self-cleaning hutches is that the floors are always dry; the principle of these hutches is in the spaced floors. Many improvements have been marle since the first ones we built.

The required floor space for a single doe and litter is $21 / 2$ by 4 feet. Many breeders do not give their animals this much space but a smaller space will not allow the room really necessary for the young to grow as they should, bucks also require this 
much space on account of their activeness. The height should be no less than 18 inches in front to 1 foot in the rear; more height is better. Always make your hutches wide and narrow-meaning 4 feet from side to side and $2 \frac{1}{2}$ teet from front to back. The reason for this is that you can reach in and grasp the rabbit without having to get a pole or some other instrument to enable you to catch the rabbit. Then, too, if you malie solid floors you can give the floors the proper slant, which is 3 inches, slant-
A doe should never be bred under 7 months of age, while $S$ months is better. The same applies to the buck, and I do not advise breeding does oftener than every 10 weeks. Breed the doe when her young are 6 weeks old, leare the youmg with her another week, wean them and give the doe the other three weeks to herself.

The big mistake or rather one of the big mistakes that the beginner makes is weaning the young too young; most of then believe that the young should be weaned at 4 weeks,

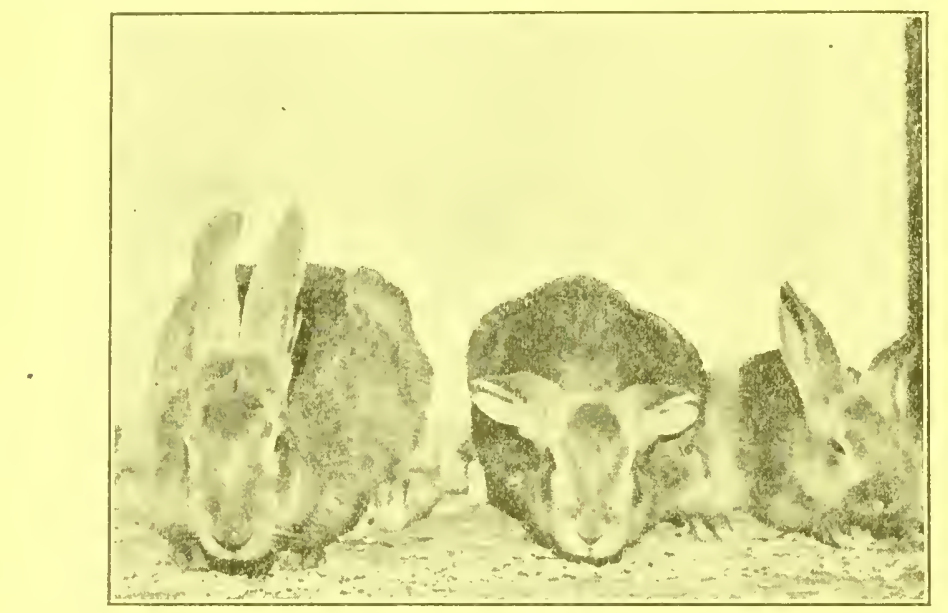

THIS CUT SHOWS HOW YOUNG NEW ZEALANDS GROW

Their ages are one, two and three months

ing from the back of the hutch towards the front.

There is but one way that you can raise rabbits on the ground and that is by moving the pen to new ground every week or so, for if rabbits are left too long in one place the Coccida germ begins to breed and coccidossis is deadly to rabbits. This germ breeds in the filth that accumulates, or in the poisoned ground caused from the continual urinating of the rabbits.

\section{BREEDING}

The most important thing to bear in mind in breeding rabbits is nature, the nearer you can follow nature the better. a great mistake this and one that amounts to total loss.

In breeding the doe always take her to the buck hutch, place lier with him for a few minutes, if she refuses to breed remove her and try her again the next day, and so on until she breeds. There is no positive way of telling when the doe is ready to breed, with the exception of the enlarged appearance of the external organ and sometimes she will appear restless.

One service from the buck is sufficient. We do what we call testing, that is, five days after the doe breeds we try her to the buck again. It she 
whines we are sure that she is bred. lf she is not bred she will probably accept service again.

It is a wise plan never to breed old does to old bucks but old does to young bucks, and young does to old bucks.

The value of a good buck can not be overestimated. If you have some fair stock you can greatly improve same by purchasing a first class buck. If it is exhibiticn stock you have, then it is up to you to purchase the very finest buck that you can afford. Our buck, "Gilmore's Red Wonder," produced over $\$ 1000.00$ wolth of stock. His value was $\$ 50.00$, so you see how profitable a good buck is. This was during the year of 1916 .

The natural breeding time of the rabbit is during the spring months, although they breed during every month of the year; they do not, however, breed as readily during the last six months of the year as they do the first.

The average useful life of a rabbit is four yeal's, after this age they generally produce inferior offspring.

The proper way to carry a doe to the buck hutch is to grasp hel by the loose skin on the back of the neck; never handle them by the ears.

If a doe proves stubborn about breeding, place her in a hutch which a buck has previously occupied and feed her on soaked peas; do this for two or three days.

Never let your bucks serve more than three does a week; two would be better. If a buck appears to take no interest in a doe when placed with him he is either too fat, too old, or perhaps too young.

\section{FEEDING}

Feeding is very important and it requires quite a little time and practice to become all efficient feeder.

One of the reasons why rabbits are becoming so popular is the fact that the food that they require is much less expensive than that required by chickens or pigeons. Rabbits will exist on green feed alone, but results ob- tained from feeding green feed alone are never satisfactory, especially with the youngsters. This is where the old idea comes in that rabbits do not require water. If you feed nothing but greens, then they do not require water, but if fed properly they should always have water before them.

Feed mornings either carrots, rolled barley or mash; at night, alfalfa hay and greens. We only feed twice a day. Wre have found the mash to be much more reasonable than rolled barley and we get the same if not better results. One large carrot will make a good breakfast for a rabbit. As to the greens fed at night with the luy, I will say that we have tried almost every kind of greens known and we have found that the ideal green feed for rabbits is chicory. Alfileria is also splendid, swiss chard is another good green-in fact nearly all kinds of grasses or vegetables are good. We only advise against feeding cabbage, kale or cauliflower. These greens are too severe on the kidneys and will bloat. They also give the rabbitry an awful odor.

The question aslied by all heginners is "How much do I feed?" I have suggested a handful of this and a handful of that, but I find that there is considerable difference in some people's idea of a handful. So to be more exact I made up the following table of weights:

Feed required for one rabbit over five mouths of age per day: Mash 3 ounces, or rolled barley or oats $21 / 2$ ounces, alfalta hay 5 ounces, green feed 10 ounces.

For a doe with six young, one month old: Mash 14 ounces, or rolled barley or oats 12 ounces, hay 14 ounces, gleens $1 \frac{1 / 2}{2}$ pounds.

Doe with six young, two months old: Mash 28 cunces. barley or oats $2 S$ ounces, hay 1 pound. 2 ounces; greens $2^{1 / 2}$ pounds.

The above table is just what is required for a good healthy growtl, but if they are to be raised for market, mash and hay may be before then at all times.

Now that I have given you the food 
staples, etc., let us get down to food costs. I am going to reprint the fol. lowing by Mr. C. I. Hunt of Hunt, New York:

"In a recent test to determine the pxact cost of raising rabbits for meat purposes we took twenty-two and placed them in a run by themselves, keeping a strict account of all feed used. The result is shown herein. The twenty-two weighed 118 pounds when sold and brought $\$ 20.31$. Expenses: Feed, $\$ 7.08$; express and commission, $\$ 4.13$; total cost, $\$ 11.51$; leaving a net profit of $\$ \$ .80$, or 40 cents each. Had they been sold at home they would have brought a net profit of $\$ 13.23$ or 60 cents each. The feed cost to produce live weight was 6 cents a pound."

We figure on 11 cents per pound for dressed stock which sells for 35 cents per pound on the local market.

The food cost depends altogether on where you live. In some places alfalfa hay is twice the price it is in other places; then, too, if you can raise some of your feed this will bring the feed cost down.

Most breeders feed too much; this causfs waste and makes the breeding stock too fat and fat breeders give vely poor returus. It is a hard matter to feed a cloe with young too much hay or mash, but be careful in feed. ing other stock, and don't overfeed for the sake of your pockethook and the rabbits.

\section{GENERAL CARE}

In the general care of your rabbits just keep in mind these essentials: sanitation, cleanliness, pure fresh water, regular feeding, proper breeding. small litters, weaning at the proper age and pure fresl air.

The rabbit is naturally a very dainty animal and you camnot raise them under the same conditions and with the same disregard to sanitation often shown a hog. Do not overlook the fact that disinfecting is very important. We have a large spray pump and once a week we go over the entire rabbitry, using a good strong disinfectant. For this we have found Mayhew's exceptionally good, on account of its non-poisonous character. Good slaked lime should be sprinkled on the floors every time you clean the butches. (This is of course unnecessary in our seli-cleaning hutches, although even these should be sprayed good every week or so). Keep the ground clean around the hutches, also whitewash your hutches inside and out; this will give them a much better appearance, make them lighter and will keep down germ enemies.

The very finest cure for rabbit ailments is "Prevention." lieep your stock under sanitary conditions, feed properly, etc., and you will need no "Rabbit Dope." In case a rabbit does become ill, exile it at once from the rest of the stock and use the best remedies obtainable. If a rabbit remains ill for more than a mouth with no signs of recovery, give it the axe. Snuffles is probably the most serious disease of the domesticated rabbit, with the exception of Coccida, which is very rare, being caused from very unsanitary quarters. Snuffles is either caused from poor air or comes from weak vitality; once this disease gets a good hold of the rabbit there is nothing that will cure it. Ear Canker is the most common disease of rabbits; it is a little parasite that can be seen with the naked eye if you look closely enough. This parasite eats the lining of the inner side of the ears, causing it to scab. This is very easily cured and generally requires about two applications of a good remedy.

One thing that breeders do not pay enough attention to is the nest box. This is very important inasmuch as it broods, so to speak, the little rabbits. First it must be large enough, $12 \times 12 x$ 18 , is a good size. Second, the onening must be made so that the little fellows cannot be dragged out by holding on their mother's teats. Make it no less than 5 inches up from the floor and no less than 4 inches wide, have the lid on hinges or a nail in one cormel so that it will swing around. Use good nesting material. We have tried about everything and find common engine waste about the best 
thing yet. Never use alfalfa or clover hay. Good oat straw is good. In winter time fold a burlap sack and place over the bottom, also place four or five old newspapers minder the sack. Cold, as you know, ccmes up from underneath. I will venture to say that thousands upon thousands of little rabbits are frozen every winter because the breeder does not know the importance of the proper care of the nest box.

\section{CARE OF YOUNG}

As I have previously stated, two things, in lact. the two most important things to do in raising rabbits is to not let the doe raise over six young and not to wean said young uncler seven weeks of age. If you follow and by the time they are seven weeks old there will probably be four or five left. which will weigh about half as much as the other five litter. I do not insinuate that it is impossible to raise litters of 10 with one doe. It is quite possible, but 1 am basing my writing on what is generally the case.

The first two weeks of a rabbit's life are the most important of its whole life practically speaking, and it is altogether how you care for the mother whether or not it will receive the proper start. Begin when the doe is bred, feed her well and be sure that she has green feed, for if she is not find greens when she is preguant said greens will not agree as well with the youngsters. Whan the little fellows

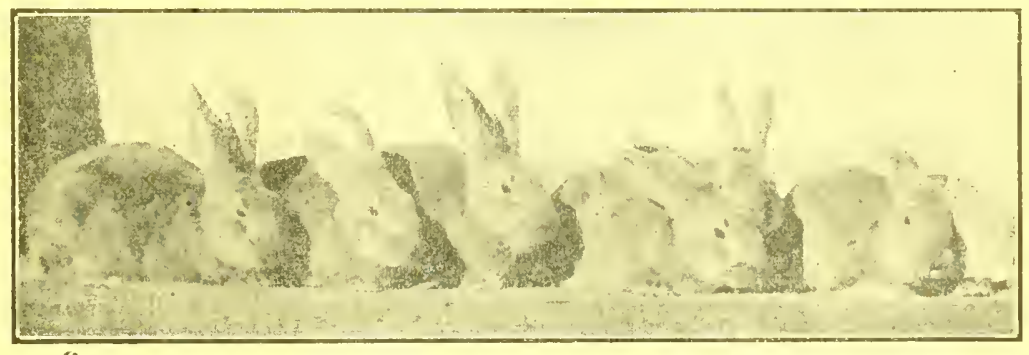

SIX GILMORE FARM NEW ZEALAND YOUNGSTERS

Age two months. Average weight $41 / 4$ lbs.

this rule you will have very little trouble in raising your young rabbits. This knowledge alone is worth many times the price of this book, becanse these are two of the greatest secrets of successful ralbbit raising. Nany do not like to cut down the litters, claiming that "I am just raising them for meat." Gentle reader, if they only knew that if they were to take two does, place them side by side, breed them the same day, let one doe have ten and the other have five, at the end of two months the five would weigh more pounds than the whole litter of ten and the chances are 5 to 1 that when the ten litter were about one month old they will begin to kick off from apparently no reason. caused from the lack of enough nourishment. are born begin feeding the doe leavily, using plenty of greens ta good sized handful niglit and morning). keep mash before her all day and give plenty of good hay. When the little fellows begin to come ont of the nest box feed less greens, otlerwise make no change in the feed. only to give more mash or grain and hay. Clean out the nest box on the 14th day and re-bed with good clean straw.

\section{NURSE DOES}

Let us suppose that you have a very fine dce which you have purchased from some big breeder, said doe has ten youngsters. It is a hard matter to have to cut this litter down to 4 or 5 youngster's. Now the way we get around that is to hreed an ordinary 
doe at the same time that the fine doe is bred, in a day or so after they luave both kindled we destroy the young of the ordinary doe and give her half of the fine doe's litter. It is always best to do this about $S$ ciclock in the moruing, as the nurse doe will probably not go into her nest box until that evening when she feeds them. By this time they have taken on the scent of her nest box, and she cannot tell the difference. Some brefders put a little eucalyptus oil on her nose, but I have never done this. So far I have had very little trouble in setting the foster mother doe to take the young.

\section{THE NEW ZEALAND RED RABBIT}

The New Zealand Reds are. strictly speaking, business rabbits for general or utility purposes. They do not belong to the ormamental classes, yet bit we were raising. At the present time they are the most popular rabbit in the country. Why? IVell, let us see.

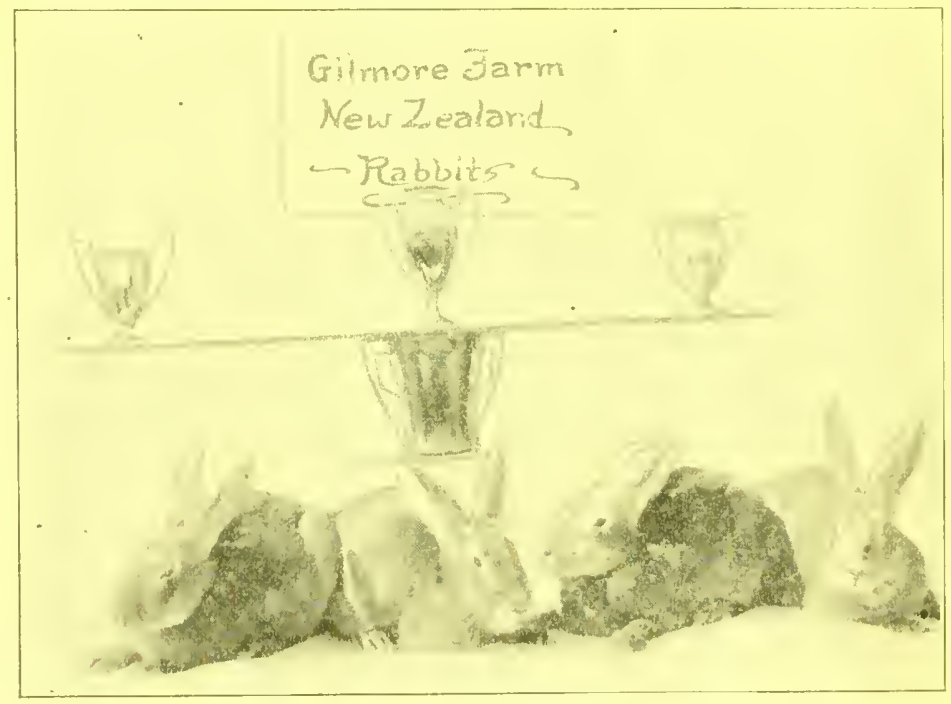

THE FOUR NEW ZEALANDS WINNING "BEST DISPLAY" OF

NEW ZEALANDS AT THE "WORLD'S FAIR,"

SAN FRANCISCO, 1915.
They are "Gilmore's Red Wonder, "Wai Apoo," "Princess Zealand" and "Gibson Girl."

they are among the most beantiful of breeds. Their bright reddish buff coloring, their big hazel eyes and handsome type makes them a much ad. mired labbit.

The New Zealand is practically a new rabbit in the American fancy; it was only about three years ago that we olganized the New Zealand Red Club and began to inform the American public just what an excellent ral).
First. As exhibition rabbits they are unecu a led ; they are by no means an easy breed from which to produce 90 per cent animals, which makes them all the more favored as an exlibition rabbit.

Second. The prices obtained for good exhibition specimens makes them very profitable.

Third. The fact that they are a new breed makes the breeding stock branch 
very profitable. Veryfew of we breeders can supply the demand for our stock. Last year we ran over 200 animals short of our orders, ateraging them at $\$ 5.00$ each means quite a little money.

Fourth. As a market rabbit they are par excellence; practically all the large rabbit breeders around Los Angeles, which has the best rabbit market in America, breed New Zealands.

Fifth. They mature rapidly, making fine fryers at from $?$ to 10 weels.

Sixth. They are medium boned. making them superior as fryers, for, taking a larger rabbit when the young begin to grom they must grow a big frame, consequently when clressed at eight weeks you have much bone and little meat. New Zealands are very plump.

Seventh. They breed very true to color. It is most discouraging to find that your thoroughbred doe of some other breed has several different colors in her litter. This is especially so if you are selling exhibition stock. Pure bred New Zealands never throw off colored animals.

Eighth. They are a very quiet breed, consequently they take on flesh very rapidly.

Ninth. The bucks, with very few exceptions, can be raised together without tearing each other to pieces until they are 7 months old. This means a great saving of hutch space as well as of extra work.

Tenth. The flesh is of fine grained texture and very juicy.

Eleventh. The rur of the New Zealand is coming in demand, being used for imitation Red Fox. We have seen a great deal of it on the streets this winter. One fur house put out several hundred sets this year.

The National New Zealand Red Rabbit Club has been a great factor in introducing this rabbit. Three years ago little was known of the breed outside of California. If ycu are interested in New 7ealands you should by all means belong to this club as it is "The power behind the Throne," and by becoming a member you are adding youl bit to the progress and prosperity of the breed. Application can be made by dropping me (who happens to be the secretary) a card. The dues are but one dollar a year.

\section{WHAT WE KNOW OF ITS ORIGIN}

The first New Zealands we have record of in this country were inported by John Henry Snyder of San Francisco in 1906 . When he returned from New Zealand he brought four does and a buck with him. Later we learned of a Mr. Henry of Los Angeles who also imported a large number.

When we first introduced this rabbit to the fancy we were met with the usual opposition that always greets anything new; in the April, 1915, number of "Domestic Pets." a Mr. M. H. Branning, who had taken up the breeding of the New Zealands, wrote an artićle about them and incidentally mentioned that the first specimens were imported into California in 1906. This article drew forth considerable comment from those who were acquainted with the Sport Belgian and Golden Fawn, which are of a buff color. They were wont to believe that they were all one and the same rabbit. Some of these parties wrote Mr. Branning, stating flatly that he was mistaken. Mr. Branning then sat down and wrote to Mr. Jas. Duncan, Acting Director of the Department of Agriculture of the Dominion of New Zealand and the following is the reply he received:

In His Majesty's Service.

Dominion of New Zealand, Department of Agriculture, lndustries, and Commerce. Advice en Field Crops -Inspection of Rabbits.

\section{Wellington, June 17, 1915.}

Mr. M. H. Branning, Los Angeles, Cal. The New Zealand Red Rabbit

I am in receipt of your letter of the ith ultimo with reference to the above.

The description you give of the rab. bit coincides with the rabbit known in the southern part of this Dominion as the Otago rabbit. It is largely ex- 
ported in a frozen state to Great Britain. Last year there were 105,752 crates of rabbits shipped away from here. In addition to this there are two timning factories that make up the flesh of the rabbit.

This Rabbit was originally imported into this country in the early days from Scotland and was known as the Scotch Rabbit.

(He then goes on to tell how they breed and so forth and sigms himself) Jas. Duncan, Acting Director.

This letter is in my possession and can be seen by any one at any time.

The first or original New Zealands were of a much lighter color than are the ones that we have today, in fact there are almost four shades between the ones of four years ago and the ones of today. They also weighed about seven pounds, but were extremely hardy and healthy.

As you will note, Mr. Duncan states that the original specimens were imported from Scotland to New Zealand. Now just what cross the Scotlanders made to produce this rabbit we could not say, but it is very evident that the cross was well established, for the pure bred New Zealands never throw "Sports" as do our other crossed or made rabbits.

(Note.-A "sport" is an animal of different color than its parents).

\section{HOW TO JUDGE NEW ZEALAND REDS}

Describing the standard of perfec tion as arranged by $C$. P. Gilmore and Judge C. S. Gibson and aclopted by the National New Zealand Red Rabbit Club and the National Rabbit and Pet Stock Association, July, 1916.

(Please bear in mind that the following is a description of the perfect New Zealand Red Rabbit, of which there are none. We are striving to produce such an animaí or animals and consequently the closer we are able to approach this 100 per cent animal the more valuable is the specimen).

\section{Disqualifications}

First, what are disqualifications? Disqualifications are deformities, foreign coloring and faking.

The disqualifications of the National N. Z. Club and N. P. S. A. standard are: Lop ear (fallen), crooked feet, other than hazel eyes, wry tail (crooked), white bars on front feet, faking on the ages of jumiors in the junior class, plucking or dying.

Lopped ear is a case of an ear over which the rabbit has lost control and is caused by hot weather. It hangs down to one side and gives the rab. hit rather a lop-sided appearance. Crooked fept does not mean flat feet or feet which lay flat from the first joint to the toes on front feet but feet that turn out to one side, but while flat feet is not a disqualification it will count against a specimen on the judging table. White bars on front feet means two small stripes of white ruming around the front feet about at the joints. This is of course on the front side, faint flakes are not a disqualification, but are not desired in the perfect animal. Faking on the age of juniors in the junior class, this means entering specimens that are over six montlis of age in this class and faking their age on the entry blank. Plucking means pulling out patclies of white or black hairs. Dyeing means using dye to try and color up white $\mathrm{Cr}$ black to produce even color.

\section{Standard Weights}

The standard weights of the New Zealand Red are as follows:

$41 / 2$ pounds at 3 months.

6 pounds at 5 months.

$\&$ pounds at $\delta$ months.

Does 10 pounds at 12 months.

Buclis 9 pounds at 12 months.

As a rule the animals are not fully developed until they are about 16 months of age. Does develop considelably after breeding. In order to produce standard weights not more than five young can be left with the doe and four is better; our average is four and with our best grade of stock three is the limit.

In using the score card, cuts of 
$1 / 2$ to $S$ are to be made on underweight animals. There is no cut for overweight, but specimens over ten pounds at maturity are generally fat. which will count against them in comparison judging.

\section{Head}

Medium full and shapely. Color to match body, color with as little white under jaw as possible. Points 5. Cuts that may be made $1 / 2$ to 3 .

Medium full and shapely. Now this does not mean thin or full; it means white under jaw is not wanted in the 100 per cent perfect animals.

\section{Ears}

Erectly carried, medium thick, 5 to $51 / 2$ inches long, color to match body, color free from black lacing 10 points. Cuts that may be made $1 / 2$ to 6 .

Erectly carried is plain enough in itself. Some rabbits carry their ears as though about half inclined to have lop ear, and while this is not a disqualification, it is not desired in the

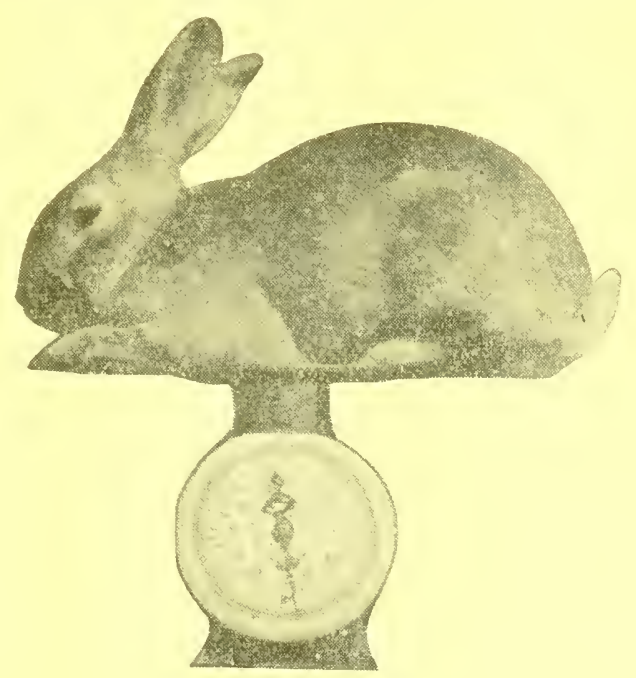

"JOHN BUNNY"

This old buck, now deceased, is the stud that put the type in the Gilmore Farm New Zealand Reds. His color was very poor.

just what it says, medium. We do not want a Flemish or a Belgian head on the New Zealand but a New Zealand head. The head of the buck is somewhat shorter in length and broader between the eyes than that of the doe. The lines should be clean cut. As to color it should be the same as the body color, but owing to the fact that nearly all present day animals have white under jaw the provision, "with as little white under jaw as possible," is placed in the standard. This is tc let the breeder know that perfect animal. As to shape of ears, I ask you to turn to the cut of "Rangiteria" and note his ears. They are a splendid example of a standard ear. The short bell-shaped ear is far from our standard ear and should be avoided. As to length they should be between 5 and $5 \frac{1}{2}$ inches, either under cr over would be out of proportion.

The color is to be the same as that of the body and free from black lacing. Black lacing is black hairs along the upper front edge of the ear. It will 
be some time before we get rid of this in oul dark reddish buff animals. At present they all have it more or less.

\section{EYES}

Large, bright and hazel, with as small a white eye circle as possible. Score 5 points. Cuts that may be made $1 / 2$ to 3 .

Some rabbits have a small beady eye, others have a sort of an almoudshaped eye. These are undesirable, as the standard calls for a large, round, bright eye of hazel color, which is a sluade of brown. The white eye circle, meaning the white hairs around the eye, is not desired and is to be as small as possible.

\section{LEGS AND FEET}

Strong and straight, medium heavy bones. Color same as body color (all

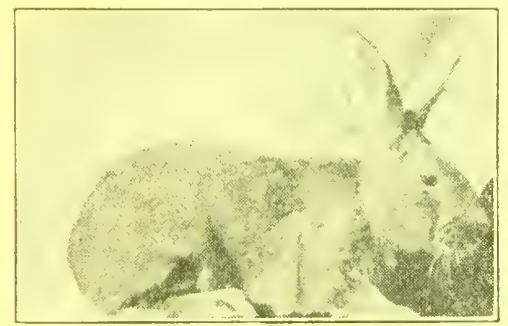

"GILMORE'S RED.WONDER"

This is the buck that put the wonderful winning reddish buff color in the Gilmore Farin Strain

of New Zealands. His type is very poor.

four feet). Score 15 points. Cuts $1 / 2$ to 6 .

Too often we see 9 or 10 pound New Zealands with legs that wonld look good on a 7 pound animal. They are small and spindly, tapering in at the first joint. So the New Standard was made to call for straight and strong. medium boned legs; not a Flemish leg, mderstand, but smaller on the same order. Color same as body, all four feet; this would mean that they are to be solid redish buff with no white llairs to be seen, even where the bars now are.

\section{COLOR}

Redclish buff, carried well down to

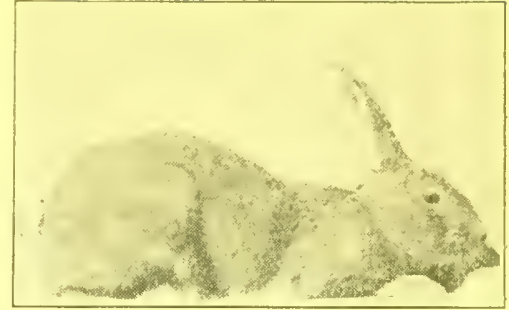

"PRINCESS ZEALAND"

A doc of botls good type and color

the skin and evenly down over the sicles and hind quarters, free from black or white hairs and not darli smudgy or light buff. Reddish cream belly color. Score 30 points. Cuts that may be made $1 / 2$ to 10 .

Color as you will notice is allowed 30 points in the score. This then makes color the most important tling in the standard, weight being next with 20 points. This is as it should be for in exhibition animals color is the big thing. You may have an anj. mal with good type and standard weight, but if it is poorly colored it will never stand a chance of wimning in competition.

New Zealand Red is somewhat le. ceiving, for the New Zealand is not a red rabbit on the order of a red Cavie. cow or horse. If it were, our stanciard would call for cherry red or some-

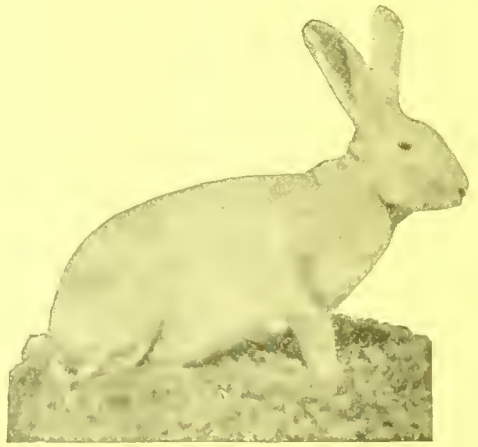

'RED RIDING HOOD"-FIRST

Prize doe Ventura, California, 1915, dam of "Rangiteria." 
thing like that, but it calls for reddish buff and to describe it mould be rather a hard proposition. Tbe Red was given the breed as a "for short" name by Los Angeles breeders. and at the time it was given them they were a long ways from being even reddish buff, let alone red. However, as the name Red is so well establisher? it will have to be let go as it is. Reddish buff is neither red nor buff: should you take some dark red paint and some buff and mix them you would have the New Zealand color. Some of the present day New Zealands rum very dark, but they show blackish or smudgy color, principally on the hear and ears and on the haunches. At first glance this blackish color cannot be noticed, but if you look closer it can be plainly seen. Then again in the lighter animals there are the white hairs. These also can be seen only by close examination; these hairs will be found principally on the back and haunches. Looking at a New Zealand from its head it will appear much redder than looking at it from behind; there is something in the way that the hairs lay that makes this, also you will notice that they are much redder at twilight than in the brightness of day.

If you are a novice with New Zealands, no doubt you will be very much disappointed with the first litter of youngsters born. 'They will appear' very light in color, but you should know that oftimes the lightest colored little fellows make the darkest colored animals when grown. They do not begin to get dark until they begin to molt out their baby coat, which is at about two months of age. From that on they darken until they are a year old, then if they are the non-fading kind they remain the same the rest of their lives, but if they are of the fading variety they will get lighter every year. Direct rays of the sun should of course be aroided if you wish to maintain the dark color.

The color on the majority of New Zealands is mostly surface color. The standard calls for the reddish buff color to be carried down to the skin. this means that the same color that is on the surface should go the full length of the hair or be the same uncler the suriace as on it. In poultrydom this is called under color and is a very important factor, especially in such breeds as the Rhode Islani Red and the Barred Plymonth Rock. The belly or under body color should be reddish cream, this comes with the red feet and legs. for the redder they are the better colored the belly will be. It would be impossible to proctuce red hind feet with white belly color.

\section{SHAPE OR TYPE}

Body medium long and medium broad fore and hind quarters, does to have even dewlap. Score 10 points. Cuts that may be made $1 / 2$ to 6 .

In the cut of Princess Zealand is shown a good type of a Standard Bred New Zealand. Notice the depth of the body just behind the forelegs, then note a cut of a pure bred Belgian posing in the same position that she is. The belly line of the Belgian curves upward from the hind quarters to the neck, giving the animal a very racy appearance.

The cut of Rangiteria gives one an idea of good New Zealand type; note the ears, they are 100 per cent in type.

If the New Zealand has correct type they will weigh up to standard at maturity and will not appear fat, but if they haven't correct type they will have to be hog fat to come up to standard weight. The dew lap is a small growth of loose skin underneath the lower jaw, on the front of the neck, and the standard says that it should be carried evenly, meaning that a large pouchy dew lap or one that hangs to one side more than to the other is not desired. The dew lap on the does is larger than on the bucks.

\section{CONDITION}

Full in coat and solid fiesh. Points 5. Cuts $1 \frac{1}{2}$ to 3 .

For explanation of "Condition." see "Conditioning fer the show room."

\section{MATING}

When mating your New Zealands 
keep in mind the disqualifications of the standard, providing of course that you are breeding for exhibition. No animal with a disqualification slould be used. If you have à fine colored buck with short ears and a doe that is not quite so well colored but tluat has fine ears, mate them and lool the best results for your next breedings, etc. Always go over your does before breeding and try and figure out just where they lack, then choose the buck that you think will bring up these points. Never breed a doe with poor type to a buck with the same failing. Never use animals that are not in good condition and strictly healthy. Do not breed from New Zealands that do not hold their color mole than one year; if you have sucl animals get a sood non-fading buck from some reliable breeder who has nonfading New Zealands.

\section{LINE BREEDING}

The foremost breeders of live stock use line breeding in order to preserve and yet at the same time improve the blood of their best stock. A beginner wishing to establish line breeding should select the very best pair or trio that he can afford to buy from scme well known reliable breeder who has line bred for years, always selecting quality in preference to quantity.

The young from this pair will be 50 per cent male blood and 50 per cent female blood. Now select your best does from the litters and mate them back to the sire. The young from this mating will be $3 / 4$ male blood and $1 / 4$ female blood. At the same time mate the original or old doe to the best young buck raised which will give vou $3 / 4$ female blood and $1 / 4$ male blood.

Now you have rabbits from the two matings with $3 / 4$ female blood on one side and $3 / 4$ male blood on the other sicke. It is now a good policy to introduce new blood from the same strain by purchasing a good buck from the original owner of your foundation stock. Mate lim to either lot of females and the young bucks and dors from this mating can safely be crossed with either of the $3 / 4$ blood lines, with little danger of weakening the vitality of the stock.

Some breeders prefer to introduce the new blood through the female side, thus keeping the strong male line unbroken. The original male is often mated to the thirl generation or $3 / 4$ male blood does.

If you intend to line breed you must make up your mind to keep a strict account of all your stock. for in no other way will you obtain results. There is no question but that line breeding is the greatest method to establish a prize winning strain. In poultrylom all such breeders as $W$. D. Holterman, E. B. Thompson, Lester Tompkins, Cecil Shepherd, Mrs. E. B. Martin, U. R. Fishel, John S. Martin and others who take a string of birds into the show room and come away with every first prize and in many instances every prize offered, all line breed; in no other way could they produce so many grand fowls. I have seen several fine New Zealands that were what we called chance matings. In one case I raised a beantiful young buck, I had great hopes of doing things witl him, but, O me, O my, when his young were old enough to qualify they were sold as utility stock.

In line breeding my own stock I had several different bloods to start with and by choosing the best of each litters for some five vears I am able to keep within my own strain, for as you must understand the further away you get from your original mating the easier it is to make your selections for mating. Not so long ago I went out for a buck and was fortunate enough to purcliase a buck which came from the only othel man in the country that I know of who line breeds New Zealands, thus I lid not stand a chance of going back so to speak when I introduced new blood.

Incidentally I might mention that the four first prize New Zealands at Jos Angeles owned by me are of $m y$ line bred stock.

PEDIGREEING AND REGISTERING

Tutil just recently it has been a hard matter to purchase New Zealands 
with pedigrees extending back nore than one generation. The reason for this is that the first breeders to take them up paid no attention to their pedigree and consequently it has taken some time to establish strains of pedigreed stock. I am often asked why purchasers mish a pedigree. The reason is this: Let us say that one wished to purchase a buck to improve his breeding stock, supposing that he purchased a youngster sired by Rangiteria who in turn is sired by Gilmore's Red Wonder, now when you go to sell stock from this buck you can show that he has fine breeding back of him, the pedigree is really family history and it is a question whether cer- ing every year ant it is a good plan when pulchasing exhibition stock to demand that it is sirerl and damed by registered animals. The fee for registering is $\$ 10.00$ per animal.

\section{CONDITIONING FOR THE SHOW ROOM}

If you wish to win in strong competition you must have your stock in proper condition. Conditioning is far more important than one would think, the finest rabbit in the world could not win if it were in poor condition. To begin with you must begin the day

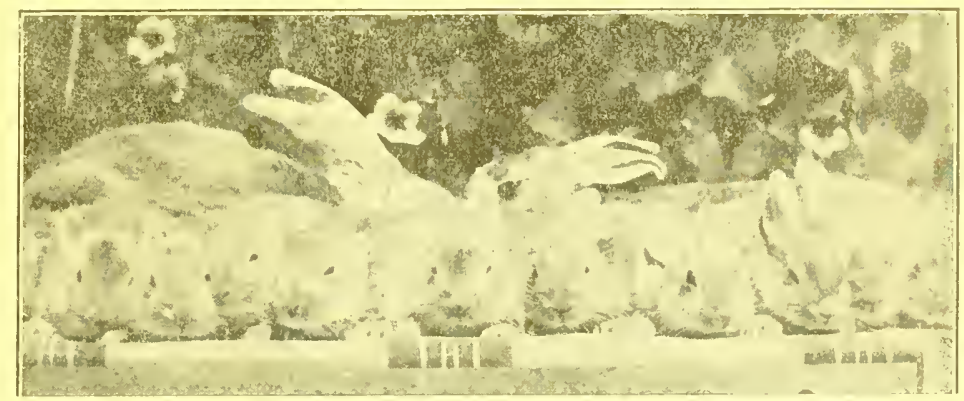

ONE OF OUR DOES, HER LITTER OF ELEVEN AND HER NURSE DOE

tain stock came from high brow or low brow families. The perligree gives the name of an animal's parents, grandparents and great grandparents on both sides.

Registering is a guarantee of good stock; no animal call be registered unless it is of good quality; an animal having disqualifications is barred. All animals must be pedigreed for three generations, which guarautees that it is a pure bred. If you have an animal which you wish to register write to the National Secretary, and ask hin where the nealest registrar is to you. You ship the animal to this man for him to pass on and if favorable he will tattoo the official number in the par. The name that you give this rabbit is then copyrighted. The demand for stock from registered stock is grow- that they are born and from then on they must receive the best of care. Never breed does until after your show season is over. for once you breed an exhibition doe it is almost impossible to get her in good show condition again. Nine months old malies fine Senior animals while bucks show up well for 18 months. TVe breed for our Seniors in February and do not use them until after the winter show season is over.

About 30 or 40 days before the stock is to go to the show room begin to groom their coats. This is done by rubbing with the hands every day; put a few drops of glycerine on the hands and rub briskly, do not get too much for you will make the hair sticky. Then about 15 days before the show rub with a chamois skin or a 
silk handkerchief. Feed a teaspoonful of linseed meal every other day in their masl and be sure and give good greens, not too mucls but enough to heep their bowels in good condition. These help to make the coat glossy. Never enter a New Zealand in bad molt, for remember that the judge judges the animal as it appears on his judging table, and not what it will be or has been. If the animal is in bad molt he cannot tell what it will

\section{THE NEW ZEALAND RED RABBIT By Hale Prather}

(Mr. Prather is the President of the National New Zealand Club, and one of the leading breeders and boosters of New Zealands in the country.)

The New Zealand Rabbit, perfect in all sections as set forth in the new Standard of Perfection, has never been produced, in fact nothing has ever been proluced that is much more than

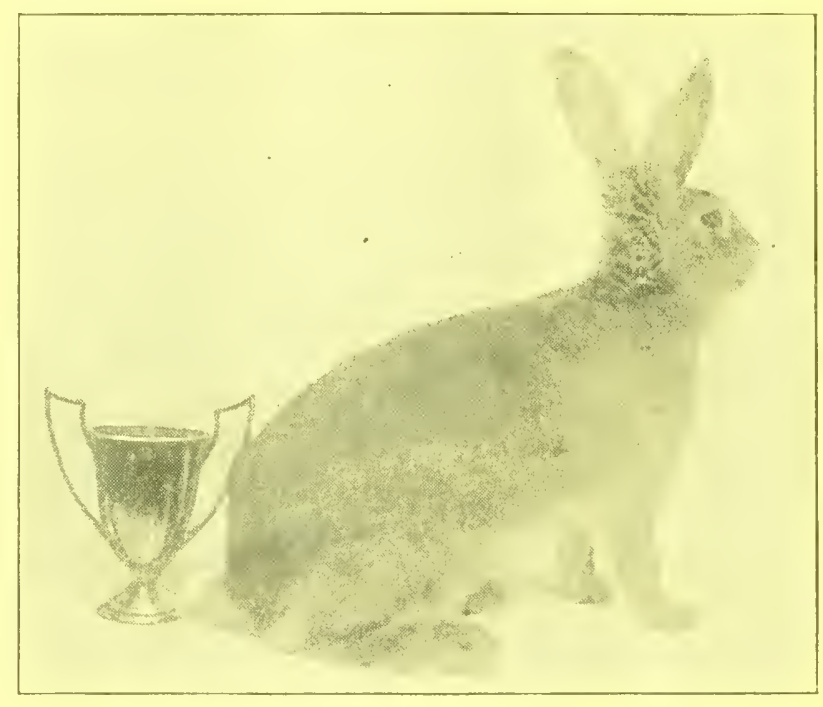

"PRINCESS ZELZAH"

Winner of the silver cup awarded for best New Zealand in the Show at San Jose, October, 1916, a daughter of "Princess Zealand."

be when fully molted out and could not give it first place over an animal in full coat.

We began on the seren New Zealands entered at Los Angeles (1917) 40 days before the show and spent from one to two hours every day working with them. Needless to say they were in splendid condition when placed on the judging table and said splendid condition helped them to win in such classy competition. a mere approximation of the standard. Our idea in fixing a high standard was that it would thus improve the rabbit more rapidly than would be the case if we set a low standard, which nearly all breeders in the country could breed to without difficulty. A low standard also tends to lower the prices on the best specimens and to decrease the interest in breeding the variety. Under the standard which we now have, if a man produces a specimen that comes well up to the standard he will be able to get a price 
for it that will pay him well for his trouble. It will be extremely difficult for any breeder to produce a perfect specimen for years to come as there are so many things that are sadly lacking in even the best specimens of the present time. The extremities are the hardest thing to get up to the standard. Several breeders have now produced a very good color on the body with creamy belly, but when it comes to having the color of the ears the same shade of red as the body and no black lacing on them, no white under the jaws, very little white around the eyes, no black or white hairs in the fur, and all four feet solid red without even flakes, let alone bars, they are sadly lacking as yet but we are getting there slowly. If breeding simply amounted to mating a rabbit with extra fine body color but lacking on feet and head color with a rabbit very strong in these points and having the litter come with the strong points of both sire and dam and none of the faults of either we would soon have perfection, but from sad experience I find the faults are just as apt to appear in the offspring as the good points, in fact the young may have most of the bad points from both specimens and very little of the good.

To breed high class specimens it is absolutely essential to have stock that is from high scoring ancestors. I would rather use a specimen that was from winning parents and grandparents if he has perfect health and vigor and no disqualifications, even if he does not approach the standard as close as another buck of great individual merit, the result af a chance mating, and no record of what kind of rabbits his ancestors were. It is surprising how the young will divert back to their parents and even stronger back to their grandparents.

Also in breeding for exhibition points we must never lose sight for an instant of what the New Zealand rabbit has been produced for, that of raising a meat rabbit that will produce a maximum amount of white, juicy meat in the shortest possible time. Even if a rabbit in my hutches has extra good color and all around fine points and does not show a quick and early development into a round meaty rabbit considerably over standard weight at three months of age, 1 do not care to use $\mathrm{him}$ as a breerler. I am satisfied that careful selection of quick maturing specimens as breeders will eventually help us out greatly along this line. Investigation of the markets will show that the demand is for young rabbits weighing from 4 to 6 pounds, or about the right size for the ordinary family. Stock weighing over that is subject to a cut on the rate per pound and 10 and 12 pound specimens are not desired at all, in fact can hardly be forced upon the aealers. The breeder of market rabbits should market his stock at not over 4 months of age to get the most profit, and the rabbit that. will produce the largest amount of meat at that age is what is wanted. With the larger breeds it is necessary during the first few months of their lives for them to use the feed they consume to build their big long frame and heavy bones, while the medium coupled, fine boned. New Zealand will begin to lay on the meat from the start. Take a 5 pound New Zealand Red and one of a heavier breed weighing the same and remove the meat from the bones and you will find there is considerable more meat on the New Zealand. In lact the other breed would lave to be considerably heavier to equal the New Zealand in the matter of edible meat.

From the above it can be readily seen that the New Zealand Red breeder certainly has his work cut. out for him, as there is room for improvement all along the line. The breeder that starts with good stock and is always striving for improvement will find a ready market for all his product at top notch prices, and as the New Zea. land rabbit gradually takes its proper place more and more in the economic life of the country the price of the best specimens will grow larger and larger. As proot of the prices that are being paid for the best New Zealand specimens even now, I would say that the buck that won first senior at the 
P. P. I. E. show has been sold for $\$ 40$, and was worth every cent of it, and a like amount has been paid for the doe that won first senior at the same show. There is certainly no danger of over production as 1 see it and the future of the wonderful New Zealand rabbit certainly looks bright.

What is prettier than a nice bunch of New Zealands? No other breed can compare with them in looks and they are far ahead of chickens to eat. I find them very healthy. In my two years of raising New Zealands have lost but two with no other sick ones. For the party in town who wants to make money and have first class meat for theil table at all times of the year, get a pair of New Zealands to start with and see how well you can do. New Zealands for me every time.

\section{WHY NOT NEW ZEALAND REDS By Fred M. Youngs}

(Mr. Youngs is a Director of the New Zealand Club and a pioneer breeder.)

As a lover of pets, we have kept rabbits from boyhood. From a fancy and fad it has developed into a commercial sideline, which has added interest to our hobby by making it a paying pastime. We started with Belgian hares, and, like most fanciers, we became imbued with the frenzy to produce the standard of perfection; to get that desired slim, racy shape, deep Rufus red coloring, etc., and we thought we had attained some wonderful results, and from that standpoint we did, as have many other breeders. But what have we produced? From my own experience I have found that this system of fine breeding has depreciated the commercial value of this once famous Belgian hare. From a hardy, prolific, meat-producing stock they have degenerated into a delicate, nervous, dainty thing of beauty, for show purposes only.

About six years ago we secured a start in what has since become widely known as the New Zealand Red. From our foregoing remarks we do not want to be understood that we do not believe in improvement; we certainly do, but on broad, general lines that will enhance the conmercial value as well as the fancy, and we stop at no expense in the selection of stock to bring about this result. We have found in the New Zealand a breed that meets with all requirements.

Their own natural grace and beauty make them an attraction in the show. Today no pet stock show is complete without them. They are a great advertisement for their exhibitors. At every show where I have exhibited my New Zealand stock I have received tempting offers, far in excess of my usual selling prices, and I know that every exhibitor of these beauties has completely sold out his surplus stock shortly after each show season. Everyone who buys the New Zealands is delighted with them, and finds how true they breed to color. They immediately become members of the Boosters' Club in belalf of this favorite. They will enthusiastically tell you that they grow more rapidly than the Belgians and are larger at maturity. They are equal, if not superior, in flavor to the meat of any other breed. While the standard of perfection for this breed is not so easy to attain, the selected few always bring fancy prices, and the balance maintain a firm quotation as utility stock, which is the staple end of the business.

The New Zealands are not shaped like a race-horse or dachshund, but are graceful and beantiful in both color and shape. They are not nel. vous and irritable, but domestic and contented. They are prolific, the does are good mothers and have large litters.

The young develop quickly with small loss in mortality. They certainly meet all requirements, both in the fancy and commercial utility, and from our experience we are convinced that without the utility the business of our rabbitry would not long survive.

A large per cent of those who buy stock want good healthy, hardy utility meat producers. They want good stock 
suitable for that pulpose. They buy from a reputable preeder who advertises such. It is a satisfaction to please them and see them get results.

I advertise in pet stock and poultry journals and good country weekly papers. When I first started to advertise the New Zealand in comnection with other breeds I got some inquiries, but sold few. To better introduce them 1 offered one as a preminm to those who purchased a trio or more of any breed. This ploved very suc. cessful, and in every instance 1 received orders for more New Zealands. bitry. The brooder house. which is 12 feet by 50 feet, luas windows on cne side. We placed a row of hutches, three tiers high, in the center, and another low on the side. leaving a passage-way between the two rows ot hutches, also between the center row and the windows. These windows al sliding and have wire in front so they can be open'd for ventilation if necessary. The hutches are all wire except partitions and floor, thus giving plenty of light and air. My hutches are $2 \frac{1}{2}$ by $3 \frac{1}{2}$ feet by 25 inches high and are so constructed that two can

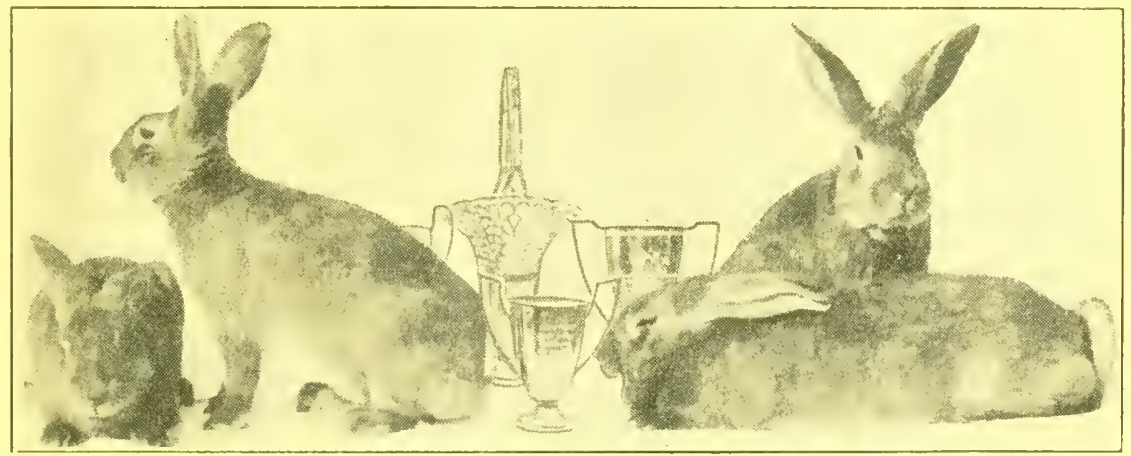

THE FOUR GILMORE FARM NEW ZEALANDS

Winning all four first prizes and four silver cups for Best Display, Best Doe, Best Buck and Best New Zealand in the show at the Great Los Angeles Show, January, 1917. They are "Lady Perfection" "Gilmore's Pride," California Girl" and "Rangiteria."

During the past two years l have added to my breeding stock, but have never accumulated a surplus, often having crders booked ahead. Much o" my stock has been shipped to eastern states. My profits have been greatly increased since taking up the New Zealand, and I am gradually working out of other breeds and hope to soon be an exclusive breeder of New Zealands.

Before starting with rabuits commercially I raised chickens. 1 learned what it was to buy wheat ancl othey. high-priced grains by that time, fight pests, etc., with much work and little profit. From chickens we save oul attention to rabbits. We turned our brooder and other houses into a rab- be opened into one, or used separate1y. The floor slightly slopes to the center, and in the center is an eightinch wide wire flocr, so that water or droppings will fall through from each tier to a galvanized pan underneath. The other houses are similarly equipped, and 1 find this style of hutch sanitary and convenient.

l water twice a day in summer, and once in winter. In regard to prices charged for stock, that depends largely on the supply and demand, same as any other commodity. A breeder gives his time to the careful uroduc. tion, as good standard bred stock shculd receive good prices. My prices range from $\$ 2.50$ to $\$ 12$ each, according to age and quality. 1 have stock 
which I have refused $\$ 2 \tilde{5}$ for. The a great deal more satisfaction in best is non too good to breed from. for I find it more profitable and get good stock.

Why not the New Zealand Red? They are the best.

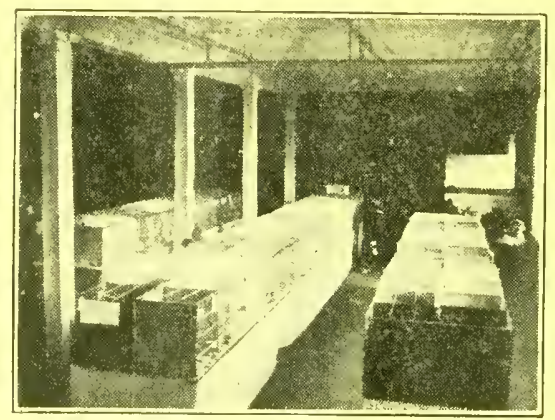

A CORNER OF THE RABBIT DISPLAY

At the great Los Angeles Show, January, 1917

\section{ifinale}

If this little book has awakened your interest in more and better New Zealand Reds it has accomplished much, if it has added to your stock of kncwlerge of our favorites, I feel wel! repaid. May it always be near at hand, a ready and reliable guide, and with this wish I dedicate it to "The Friends of The New Zealand Red Rabbit." 

LIBRHKY UF CONGRESS

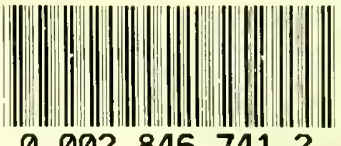

0 0028467412

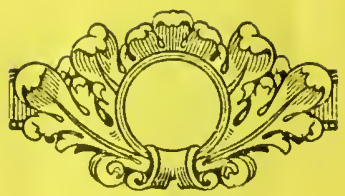

